\title{
Recuperação e renovação de bananais atingidos por vendavais e ciclone
}

\author{
Luana Aparecida Castilho Maro', Gustavo Henrique Ferrero Klabunde', Gelton Geraldo Fernandes Guimarães', André \\ Boldrin Beltrame', Ramon Felipe Scherer', Ricardo José Zimmermann de Negreiros², Jorge Luiz Malburg', \\ Keny Henrique Mariguele ${ }^{1}$ e Márcio Sônego ${ }^{3}$
}

\begin{abstract}
Resumo - Vendavais provocados por tempestades e passagem de ciclone em Santa Catarina causaram sérios danos em todas as regiões produtoras de banana do Estado. A análise detalhada dos danos em cada unidade produtiva indicará as práticas de manejo mais pertinentes para cada caso. $\mathrm{O}$ objetivo deste informativo técnico é destacar as principais recomendações de manejo para auxiliar na tomada de decisões visando à rápida retomada da produção e à manutenção da atividade econômica.
\end{abstract}

Termos para indexação: Quebra do pseudocaule; Tombamento de bananeiras; Renovação de bananais.

\section{Recovery and renewal of banana orchards affected by windstorms and cyclone}

Abstract - Windstorms caused by storms and a cyclone in Santa Catarina resulted in serious damages in all banana producing regions in the state. The detailed analysis of the damage in each production unit will indicate the most relevant management practices for each case. The purpose of this technical report is to highlight the main management recommendations to assist in making decisions aiming at a quick resumption of production and maintenance of economic activity.

Index terms: Pseudostem breaking; Falling of banana plants; Orchard renewal.

\section{Introdução}

No cultivo da bananeira as regiões localizadas em latitudes entre $30^{\circ} \mathrm{N}$ e $30^{\circ} \mathrm{S}$ são adequadas, sendo a faixa de 0 a $15^{\circ}$ norte e sul considerada ótima (SOTO-BALLESTERO, 1992). A localização geográfica do estado de Santa Catarina, por sua vez, enquadra a atividade numa condição subtropical de cultivo, o que implica uma condição marginal para o cultivo de bananeiras. Essas regiões possuem variação climática sazonal de temperatura e de precipitação pluviométrica, sendo, por isso, menos favoráveis ao cultivo convencional da bananeira (NEGREIROS et al., 2014).

Esta localização predispõe a região a uma maior ocorrência de eventos climáticos, tais como vendavais provocados pela passagem de frentes frias, temporais e ciclones extratropicais. A exemplo de outros eventos ocorridos em passado recente (SÔNEGO et al., 2007; SCHERER et al., 2018), no dia 30 de junho de 2020 Santa Catarina foi seriamente afetada por tempestades que provocaram ventos de mais de $100 \mathrm{~km} \mathrm{~h}^{-1}$, seguidas pela atuação de um ciclone extratropical no dia 10 de julho, principalmente no litoral do Estado. Nesse período foram registrados ventos com rajadas de até $169 \mathrm{~km} \mathrm{~h}^{-1} \mathrm{em}$ áreas produtoras de bananas, como foi o caso de Siderópolis ${ }^{4}$, que afetaram seriamente os pomares.

Foram verificadas nas áreas produtoras de bananas perdas tanto pelo arranquio de touceiras inteiras (com comprometimento total do sistema radicular) quanto pela quebra do pseudocaule, tombamento de plantas em produção ou na iminência de produção e danos foliares (Figura 1).

O objetivo deste Informativo Técnico é informar agricultores, técnicos, associações e cooperativas de bananicultores sobre as principais recomendações técnicas para a correta recuperação e a condução das áreas de produção de banana em Santa Catarina.

\section{Manejo do bananal}

Após o diagnóstico dos danos causados às plantas no pomar de banana, o produtor com auxílio do técnico/extensionista rural terá subsídios para tomar as decisões sobre quais procedimentos adotar. Vários fatores podem auxiliar nessa tomada de decisão. Além do número de plantas arrancadas/tombadas/ danificadas, deve-se analisar o histórico de produção do pomar. Caso seja um pomar com aspecto vigoroso e produtivo, com densidade de plantas e alinhamento adequados e possua boa fertilidade do solo, principalmente no perfil de 20 a $40 \mathrm{~cm}$, pode ser interessante investir na recuperação do bananal. No entanto, para os pomares que não apresentam essas características, a renovação poderá ser a opção com maior viabilidade técnica e econômica, ressaltando que se deve sempre levar em consideração os impactos deste procedimento, especialmente quanto ao tempo necessário

Recebido em 20/7/2020. Aceito para publicação em 19/10/2020.

http//:dx.doi.org/10.52945/rac.v34i2.1035

${ }^{1}$ Engenheiro-agrônomo, Dr., Epagri/Estação Experimental de Itajaí (EEI), Rod. Antonio Heil, 6800, Itajaí, SC, Fone: (47) 33986300, e-mail: Iuanamaro@ epagri.sc.gov.br, gustavoklabunde@epagri.sc.gov.br, geltonguimaraes@epagri.sc.gov.br, andrebeltrame@epagri.sc.gov.br, ramonscherer@epagri.sc.gov.br, malburg@epagri.sc.gov.br, kenymariguele@epagri.sc.gov.br.

${ }^{2}$ Engenheiro-agrônomo, M.Sc., Epagri/Gerência Regional de Itajaí (GRI), Rod. Antonio Heil, 6800, Itajaí, SC, Fone: (47) 33986300, e-mail: ricardo@epagri. sc.gov.br,

${ }^{3}$ Engenheiro-agrônomo, Dr., Epagri/Estação Experimental de Urussanga (EEUR), Rod. SC 408, Km 353, Urussanga, SC, Fone: (48) 34031400, e-mail: sonego@ epagri.sc.gov.br.

${ }^{4}$ http://ciram.epagri.sc.gov.br/index.php?option=com_content\&view=article\&id=3557:ventos-em-sc-tempestades-ou-ciclone \&catid=26\&ltemid= 


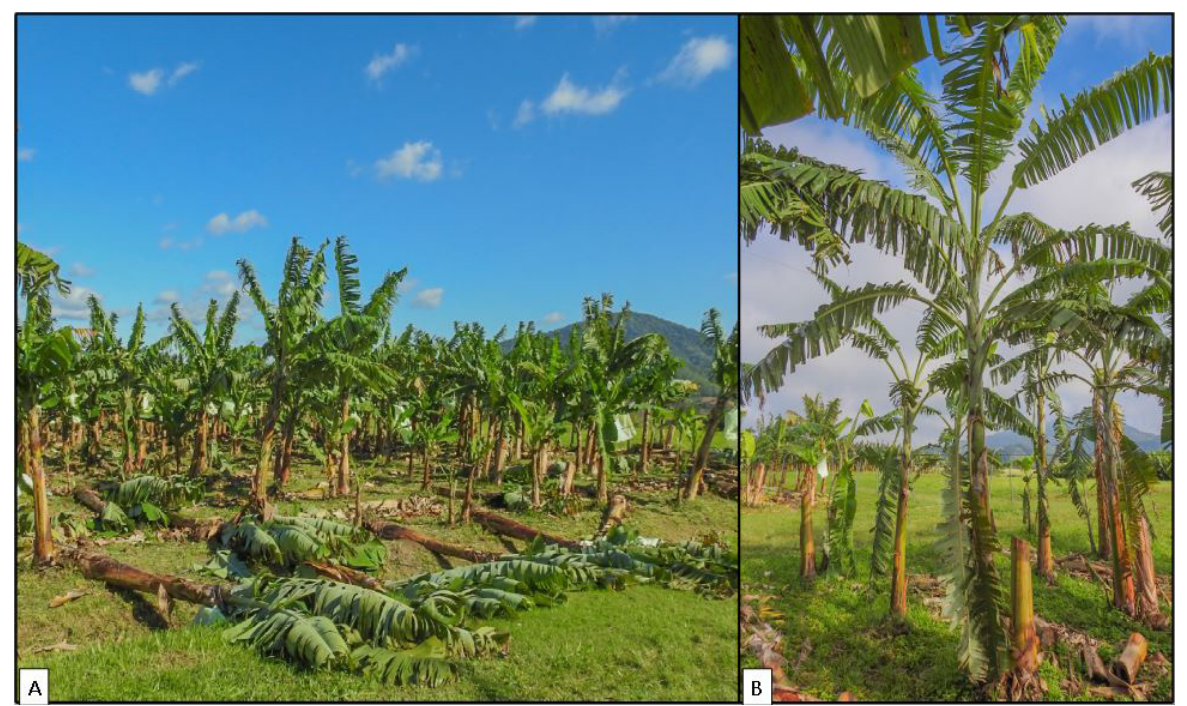

Figura 1. Visão geral (A) e detalhada (B) de ensaios na Estação Experimental de Itajaí. Itajaí, SC Fotos: Keny Henrique Mariguele

Figure 1. Experimental overview (A) and detailed view (B) in Itajaí Experimental Station. Itajai, SC

Photos: Keny Henrique Mariguele.

para a retomada da produção e da comercialização.

Poderão ser mantidas na área plantas que tiveram algumas de suas folhas com o pecíolo foliar dobrado, desde que tais folhas penduradas sejam removidas, uma vez que estas não contribuirão para o desenvolvimento da planta (Figura 2A). Da mesma forma, poderão ser mantidas as plantas que tiveram folhas com o limbo rasgado, desde que estejam sem dobraduras e com a nervura central inteira (Figura 2B). Portanto, devem ser eliminadas folhas com dobraduras (Figura 2C).

Plantas tombadas ou com pseudocaules quebrados deverão ser dispostas nas entrelinhas de plantio (sentido perpendicular ao corrimento da água) para proteger o solo que ficou mais exposto devido à formação de clareiras e para reduzir as perdas de nutrientes por escoamento superficial (Figura 2D). Além disso, a diminuição das partes da planta em pedaços menores poderá acelerar sua decomposição e a mineralização do tecido vegetal (Figura 2E).

Plantas que sofreram quebra do pseudocaule, mas que continuam com o rizoma bem fixado ao solo e sem exposição do sistema radicular, poderão ser mantidas na área. Para tanto, no caso de cultivares do subgrupo Cavendish, cortar o pseudocaule em bisel logo abaixo do local da quebra para propiciar a brotação de seus seguidores que, em momento oportuno, serão escolhi- associados à grande incidência de luz sobre as mudas, ao aumento de temperatura e à existência de um sistema radicular já instalado, permitirão um rápido crescimento dos perfilhos selecionados acelerando a produção. A vantagem desta prática em relação à renovação/ reforma total do bananal é a rápida recuperação e produção.

Em bananais em que a densidade de plantas estava abaixo do recomendado antes da ocorrência do tombamento, recomenda-se realizar o realinhamento e o replantio de mudas (provenientes de empresas produtoras de mudas credenciadas pelo Mapa) medindo cerca de $40 \mathrm{~cm}$ de altura. Já em pomares em que a densidade de plantas estava acima do recomendado, recomenda-se realizar o realinhamento e a eliminação dos perfilhos remanescentes das plantas tombadas ou quebradas.

Cachos tombados cujos frutos já tenham atingido a maturidade fisiológica podem ser aproveitados pela indústria ou até mesmo pelo mercado de fruta fresca desde que se proceda à seleção (Figura 2F).

No caso de bananais que se encontravam em boas condições de produtividade, sanidade e nutrição antes

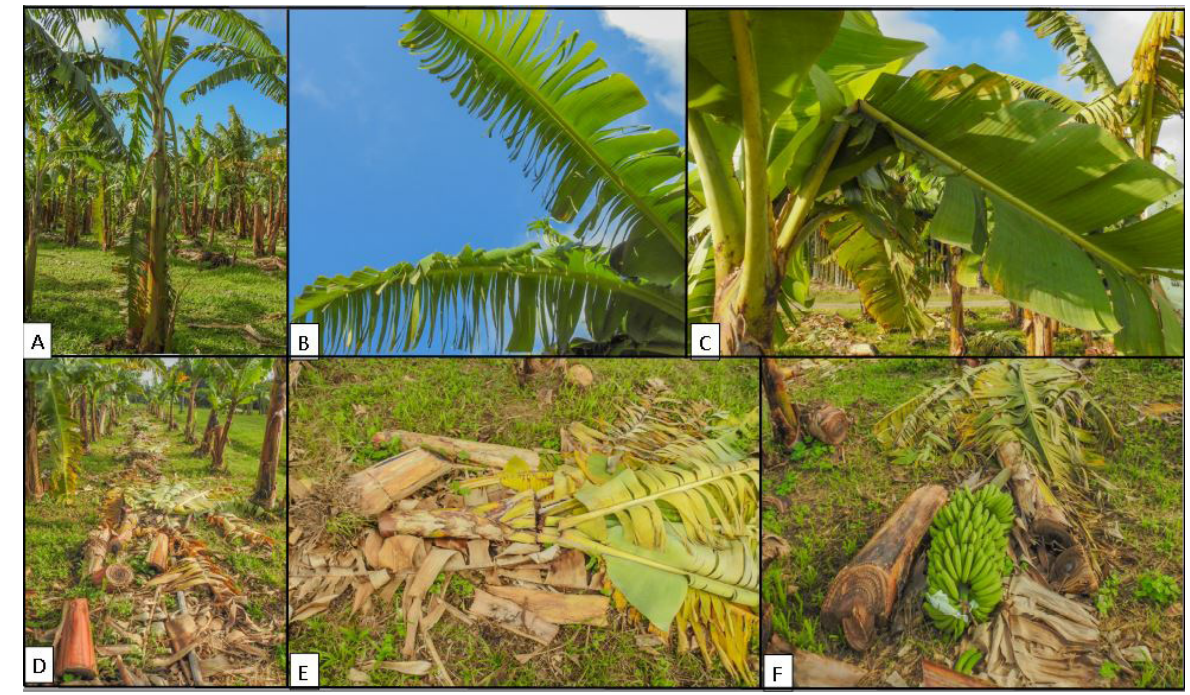

Figura 2. Quebra dos pecíolos (A) e rasgaduras no limbo foliar (B) de plantas do cultivar Maçã. Folha com a nervura central dobrada (C). Restos vegetais dispostos no sentido perpendicular ao corrimento da água (D). Planta cortada em várias partes para acelerar decomposição e mineralização do tecido vegetal (E). Cacho tombado do subgrupo Cavendish com frutos fisiologicamente maduros e possíveis de reaproveitamento (F). Itajaí, SC Fotos: Keny Henrique Mariguele.

Figure 2. Breaking of petioles (A) and tears in the leaf blade (B) of cultivar Maçã plants. Leaf with folded central rib (C). Vegetable remains arranged perpendicular to the water discharge (D). Plant cut in several parts to accelerate the decomposition and mineralization of plant tissue (E). Tumbled bunch from the Cavendish subgroup plant with physiologically ripe fruits with possible reuse (F)

Photos: Keny Henrique Mariguele. 
do evento, e que apresentem quebra generalizada de pseudocaules, sem arranquio, recomenda-se proceder como na reforma pós-geada. Ou seja, eliminar totalmente a parte aérea das plantas, mantendo o rizoma e selecionando, posteriormente, um seguidor por planta. Esta reforma apresenta baixo custo e permite a produção de cachos de boa qualidade, após dez meses, em média, nas condições climáticas de Santa Catarina.

\section{Aquisição de mudas}

É recomendado que os produtores sempre procurem adquirir mudas de empresas de produção de mudas de bananeira credenciadas pelo Mapa $^{5}$. A aquisição de mudas de qualidade é imprescindível para a garantia inicial da fitossanidade, elevado vigor inicial, crescimento homogêneo, facilidade no manejo e sincronismo de produção nos primeiros ciclos, além da qualidade genética do cultivar (EPAGRI, 2019). Deve-se verificar a disponibilidade das biofábricas para a aquisição de mudas micropropagadas.

$\mathrm{Na}$ falta de mudas provenientes de empresas produtoras de mudas de bananeira credenciadas pelo Mapa, devese procurar a assistência técnica da Epagri para a produção própria de mudas pela forma convencional (seleção de mudas e/ou produção de mudas a partir de pedaços de rizomas). A aquisição de mudas de terceiros (ou seja, que não são produtores de mudas de bananeira credenciados pelo Mapa) é ilegal e pode representar elevados riscos fitossanitários e econômicos ao bananal e à bananicultura catarinense.

\section{Recomendações de corretivos e fertilizantes}

Para os pomares que serão recuperados, a recomendação de corretivos e fertilizantes deve considerar as análises de solo, de folha e a estimativa de produção da fruta para o próximo ciclo, de acordo com o manual de calagem e adubação para os estados de Rio Grande do Sul e Santa Catarina (SOCIEDADE BRASILEIRA DE CIÊNCIA DO SOLO, 2016).
Já para os pomares que serão renovados é recomendável coletar amostras de solo na profundidade de $0-20 \mathrm{~cm}$ e de $20-40 \mathrm{~cm}$ para avaliar as limitações químicas do subsolo. Quando a área permitir mecanização, é recomendável a incorporação de calcário para correção da acidez do solo e fornecimento de $\mathrm{Ca}$ e $\mathrm{Mg}$ até a profundidade de $0-40 \mathrm{~cm}$. O condicionamento do subsolo propiciará maior aprofundamento das raízes da bananeira, aumentado o volume de solo explorado por água e nutrientes e, consequentemente, proporcionando menor susceptibilidade das plantas ao déficit hídrico e ao tombamento.

Vale ressaltar que boa parte dos pomares de banana em Santa Catarina não recebeu a incorporação do calcário antes de sua implantação e muitos apresentam a acidez do subsolo $(20-40 \mathrm{~cm})$ como fator limitante ao desenvolvimento radicular em profundidade. Portanto, nos casos que for indicada a renovação, deve-se priorizar o condicionamento do solo com incorporação de corretivos de acidez antes da implantação do pomar. Esta prática propiciará melhor desenvolvimento das plantas, maior produção de fruta e maior longevidade produtiva do pomar.

\section{Fitossanidade}

É de extrema importância realizar as pulverizações para as doenças foliares, como o complexo de Sigatoka, seguindo as recomendações do monitoramento biológico. Outra doença que pode ser agravada com o rasgamento das folhas é mancha de Cordana musae. Novamente, caso seja necessária a renovação de bananal, não adquirir mudas de rizoma de terceiros para evitar a introdução de novos patógenos na área, como viroses, nematoides e Fusarium oxysporum f.sp. cubense, com potencial de causar mais perdas econômicas.

\section{Considerações finais}

Quando se trata de recuperação ou renovação de bananais, é necessária uma análise crítica para cada situação. Eventualmente o produtor pode optar pela renovação completa do bananal por várias outras razões, além da des- truição das plantas em decorrência do ciclone recém-ocorrido. Porém, devese sempre levar em consideração os impactos deste procedimento, especialmente quanto ao tempo necessário para a retomada da produção e da comercialização.

\section{Referências}

EPAGRI. Produção de mudas de bananeira no Brasil: alta qualidade genética e fitossanitária. Florianópolis, SC, 2019. 40 p. (EPAGRI. Boletim Técnico, 187).

EPAGRI. Banana: Recomendações técnicas para o cultivo no litoral norte de Santa Catarina. Florianópolis, SC, 2016. 101p. (Epagri. Sistema de Produção, 49).

NEGREIROS, R.J.Z.; HINZ, R.H.; STUKER, H. Exigência térmica e número de dias entre a floração e a colheita para a bananeira 'Grande Naine' em condições subtropicais. Agropecuária Catarinense, v.27, n.1, p.7679, 2014. Disponível em: http://publicacoes. epagri.sc.gov.br/index.php/RAC/article/ view/586. Acesso em: 15 julho 2020.

SCHERER, R.F.; SÔNEGO, M.; BELTRAME, A.B.; MARO, L.A.C. Danos causados por vendaval em bananais de diferentes cultivares de bananeira (Musa spp.). Agropecuária Catarinense, v.31, n.1, p.4547, 2018. Disponível em: http://publicacoes. epagri.sc.gov.br/index.php/RAC/article/ view/245. Acesso em: 15 julho 2020.

SÔNEGO, M.; PERUCH, L.A.M.; LICHTEMBERG, L.A. Danos do furacão Catarina em bananeiras sob cultivo orgânico no sul de Santa Catarina. Revista Brasileira de Agroecologia, v.2, n.1, p.1210-1213, 2007. Disponível em: http://revistas. aba-agroecologia.org.br/index.php/ rbagroecologia/article/view/6519. Acesso em: 16 julho 2020.

SOTO-BALLESTERO, M. Bananos: cultivo y comercialización. 2.ed. San José: Litografía e Imprensa Lil, 1992. 674p.

SOCIEDADE BRASILEIRA DE CIÊNCIA DO SOLO. Manual de calagem e adubação para os Estados do Rio Grande do Sul e de Santa Catarina. 11.ed. Porto Alegre, RS: SBCS/ Núcleo Regional Sul; Comissão de Química e Fertilidade do Solo - RS/SC, 2016. 376p.

${ }^{5}$ Links para consulta de biofábricas autorizadas: 